\title{
Pyrolysis of whole wood chips and rods in a novel ablative reactor
}

Guanqun Luo ${ }^{a}$, Devin S. Chandler ${ }^{a}$, Luiz C.A. Anjos ${ }^{b}$, Ryan J. Eng ${ }^{a}$, Pei Jia ${ }^{c}$, Fernando L.P. Resende* $^{\text {a }}$

a. School of Environmental and Forest Sciences, University of Washington, Seattle, WA 98195, United States

b. Department of Chemical Engineering and Chemistry, Federal Institute of Education, Science and Technology, Recife, PE 50740-540, Brazil

c. Department of Mechanical Engineering, University of Washington, Seattle, WA 98195, United States

* Corresponding author. Address: School of Environmental and Forest Sciences, University of Washington, Seattle, WA 98195, United States. Tel.: +1 2062211580.

E-mail address: fresende@uw.edu (F. L. P. Resende). 


\begin{abstract}
The ability to carry out pyrolysis of entire wood chips and rods instead of small particles would be of great value for mobile pyrolysis units, because of the large possible savings in grinding costs (7-9\% of total process costs). With this goal in mind, we designed and constructed a novel lab-scale ablative reactor for fast pyrolysis of entire wood chips and even wood rods, converting those directly into a high yield of bio-oil for the first time. The bio-oil yield from fast pyrolysis of wood chips $(10 \times 20 \mathrm{~mm})$ was as high as $60 \mathrm{wt}$. $\%$, similar to that from wood crumbles $(2 \times 2$ mm). Additionally, the yield and composition of bio-oil from ablative pyrolysis were in the same range as those obtained from a fluidized bed reactor using $<1 \mathrm{~mm}$ particles, with the small differences (slightly lower yield and HHV, and higher water content) attributed to the longer vapor residence times in the ablative reactor, which promote secondary reactions. We modeled the heat transfer characteristics of this semi-batch system, and comparison with experimental measurements confirmed that radiation from the hot components does not significantly decompose the wood prior to direct contact with the hot metallic surface in ablative pyrolysis. The findings of this work have the potential to lead to new developments for small-scale, mobile pyrolysis units for the disposal of forest residues.
\end{abstract}

Keywords: Fast pyrolysis, ablative pyrolysis reactor, beetle-killed trees, wood chips, bio-oil 


\section{Introduction}

Lignocellulosic biomass is an abundant renewable energy resource. The use of biomass for energy leads to carbon neutral processes, and the chemicals and fuels derived from it have a tremendous potential to reduce the problems caused by our dependence on fossil fuels [1]. Fast pyrolysis is a promising technology to convert lignocellulosic biomass into liquid fuels or chemicals, and it has been in development for over 30 years. In this process, biomass is heated up to $400-600{ }^{\circ} \mathrm{C}$ at a very high heating rate $\left(\sim 500^{\circ} \mathrm{C} / \mathrm{s}\right)$ in the absence of oxygen, whereby it decomposes into organic vapors, solid char, and permanent gases [2, 3]. The organic vapors are rapidly cooled down and condensed to a liquid product, known as bio-oil, which is the main product of fast pyrolysis. Depending on the feedstock, the yield of bio-oil can exceed $70 \mathrm{wt} \% \%$ on dry basis $[2,3]$. Bio-oil can either be combusted in boilers, engines, and turbines to generate heat or power, or be upgraded to produce transportation fuels and commodity chemicals [2-5].

Fast pyrolysis has been extensively studied for different feedstocks, including agricultural, woody, and algal biomass [6-9]. Our previous study using Py-GC/MS-FID indicated that fast pyrolysis is a promising way to dispose beetle-killed trees by converting them into high-value chemicals and fuels $[10,11]$. Once these trees are dead, they may fall without previous warning, representing a threat to public safety, and are also undesirable for the solid wood panel manufacturing industry. To date, about 42 million acres of forests have been attacked by bark beetles in the western United States, and they are typically located far from the urban industrial areas [12]. Therefore, using a mobile pyrolysis unit to convert beetle-killed trees near the harvesting point could significantly reduce the transportation costs that are a key barrier to widespread utilization of this vast resource, since bio-oil has 6-8 times higher energy density than the green wood chips $[13,14]$. 
The reactor is the key component of the mobile pyrolysis system. Reactors for fast pyrolysis of biomass include the bubbling fluidized bed reactor, circulating fluidized bed reactor, free-fall reactor, auger reactor, and ablative reactor. For most pyrolysis reactor configurations, the biomass feedstock needs to be ground into small particles of around $2 \mathrm{~mm}$ or less, because the process requires minimizing heat transfer resistances throughout the particle [15]. Kumar estimated that the costs of biomass chipping and grinding were about 7-9\% of the overall production costs [16]. Forest Concepts also studied the effects of final wood particle size on the total comminution energy cost for the optimized Crumbler ${ }^{\circledR}$ machine, and found out that the comminution energy cost increases from nearly zero to up to $\$ 4.50$ per US ton as the wood particle size is reduced from $12 \mathrm{~mm}$ to $1-2 \mathrm{~mm}$ [17]. Fortunately, the ablative pyrolysis reactor provides an opportunity to use large pieces of wood instead of only small particles as feedstock, saving on grinding costs. In ablative pyrolysis, biomass undergoes melting and/or sublimation reactions as it directly contacts a hot solid surface. There is a steep temperature gradient at the biomass surface, leading to the formation of a thin superficial layer of reacting solid $[18,19]$. The reacting layer moves at constant velocity towards the heart of the cold biomass. Therefore, the reactive process in the ablative reactor takes place only at the superficial layer rather than the entire biomass particle, and reaction rates are not limited by the heat transfer through the entire particle. For this reason, in principle there is no upper limit to the biomass particle size that can be processed. These characteristics have been speculated in the past, but there were no experimental data to back up the claim that fast pyrolysis of large pieces of wood is possible. The major drawback of the ablative pyrolysis reactor is that it is mechanically driven and therefore more complex than other types of reactors. In addition, ablative pyrolysis is surface area 
controlled, so scaling up is difficult. However, for using an ablative pyrolysis reactor as a mobile unit, the scale-up issue is less of a concern.

To date, only a few ablative pyrolysis reactors have been developed. The first pioneering experiments with ablative pyrolysis were reported by Diebold [20], who used an electrically heated wire to cut pieces of wood. These experiments demonstrated that biomass could be rapidly pyrolyzed via ablation, producing a thin layer of liquid that vaporizes. Lédé et al. did a fundamental study on the ablation heat transfer with specific application to wood pyrolysis [19, 21-23]. However, their experimental setup did not allow for overall product recovery for analytical study and mass balance calculation. Reed and Cowdery [24] designed and constructed a "pyrolysis mill" based on the principles of a conventional grain mill. Liquid bio-oil yield of up to $48.6 \%$ (dry basis) was obtained. However, the particle size of their feedstock, pine sawdust, was only as high as 14 mesh $(1.4 \mathrm{~mm})$. The major problem of this system was the slow escape of the pyrolysis vapors from the reactor, lowering the yield of bio-oil. Later, Peacocke et al. [25] designed an ablative reactor system with four rotating blades scraping a continuous feed of pine wood, and up to $67.7 \%$ of bio-oil yield on dry feed was reported. One limiting factor of this setup was the difficult removal of the char formed on the reactor surface. The char built up below the rotating blades can quickly prevent the incoming particles from being ablated. The particle size of the pine wood feedstock was 4.75-6.25 mm, which was the largest particle size reported for tests in this system. Aston University has claimed that whole wood chips up to $50 \mathrm{~mm}$ can be processed in their ablative reactor, but no experimental data or details on the reactor design are available [26]. Recently, Paulsen et al. [27] designed a micro ablative pyrolysis apparatus in order to develop a robust wood particle pyrolysis model that accounts for both transport and pyrolysis decomposition kinetics at high temperatures and high heating rates. In the reactor, 
pyrolysis of $1 \mathrm{~mm}$ thick wood particle was conducted by direct ablation with a heated surface, and the subsequent changes of wood composition were characterized by the spatiotemporally resolved diffuse reflectance in situ spectroscopy. However, bio-oil was not collected or analyzed in their work.

Thus, we herein designed and constructed a prototype lab-scale ablative reactor to convert entire wood chips and wood rods into high yield of bio-oil in a single step. The goal is to experimentally verify if high yields of bio-oil can be obtained from large particles via ablative pyrolysis. To the best of our knowledge, our work is the first to report bio-oil production from fast pyrolysis of entire wood chips and wood rods. The results from the ablative reactor were compared to those obtained using a lab-scale fluidized bed reactor. In addition, the effect of preheating in this semi-batch reactor prior to ablative pyrolysis of wood chips was evaluated using both modeling work and experimental measurements.

\section{Ablative pyrolysis reactor and its operation}

As shown in Fig.1, the ablative reactor is composed of a chamber, which contains a spinning bowl where the wood chips can be placed, and a hot plate at the top that can move down and apply pressure against wood chips. Fast pyrolysis initiates as the hot plate contacts the wood chips, and a high flow rate of inert gas rapidly sweeps the generated vapors out of the chamber for condensation.

\subsection{Reactor description}

The ablative pyrolysis reactor designed and constructed in the present work is shown in Fig. 1. This is a semi-batch system with a capacity of $500 \mathrm{~g}$ wood chips per run. The reactor chamber is made of A240 304L stainless steel with an internal diameter of $0.30 \mathrm{~m}$ and an internal height of 
$0.42 \mathrm{~m}$. This chamber can be split into an upper chamber and lower chamber, which are connected with flanges. A static seal is created by a graphite gasket placed between the two flanges faces. The wood chip bowl made of A240 304L stainless steel has an internal diameter of $0.21 \mathrm{~m}$ and a height of $0.09 \mathrm{~m}$. In order to make the generated pyrolysis vapors escape from the wood chip bowl quickly, $0.05 \times 0.01 \mathrm{~m}$ rectangular slots were made on the shell of the bowl. To prevent wood chips from dropping out of the bowl from the slots, a $1 \mathrm{~mm}$ thick perforated T304 liner with $1.6 \mathrm{~mm}$ holes on a $3.2 \mathrm{~mm} 60^{\circ}$ triangular pitch was installed inside the shell. The wood chip bowl is driven by a 3 HP SEW-EURODRIVE gear motor, providing a rotation speed up to $160 \mathrm{rpm}$. The lower chamber contains a gas inlet and a gas outlet. To minimize the vapor residence time, the product vapors escaped out of the chamber through a perforated tube that was bent around the circumference of the bowl and connected to the gas outlet. The upper plate is driven by a piston connected to a hydraulic system, capable of moving vertically and applying a maximum pressure of 1.5 bar against the wood chips. The lower and upper drive shafts housing on the reactor chamber contain graphalloy bushings to prevent leakages and ingress of air. Three $1 \mathrm{~kW}$ Chromalox CIR cartridge heaters were inserted in the upper plate, and are capable of generating a heat flux of up to $105 \mathrm{~W} / \mathrm{m}^{2}$ and heating the plate up to $700{ }^{\circ} \mathrm{C}$. Furthermore, two band heaters (Chromalox HBT 120) were used to heat the reactor wall to a minimum temperature of $300{ }^{\circ} \mathrm{C}$, minimizing the condensation of pyrolysis vapors on the inner reactor wall. Each of the band heaters has a power of $2 \mathrm{~kW}$. The temperatures of upper plate and reactor wall are measured and controlled by inbuilt type $\mathrm{K}$ thermocouples that are connected to Chromalox 1/4 DIN temperature controllers. To minimize the heat losses, the entire reactor chamber was insulated using two layers of $1.3 \mathrm{~cm}$ thick ceramic sheets and one layer of silica fabric wrap.

\subsection{Reactor operation}


Fig. 2 shows the schematic diagram of the system, including the reactor, condenser, and gas meter, etc. Prior to the reaction, a specified amount of wood chips is loaded in the wood chip bowl. After sealing the reactor chamber, the upper plate and the reactor wall are pre-heated to the operating temperatures. During the pre-heating time, the upper plate is located at the highest position. The distance between the upper plate and the wood chip bowl bottom at this point is about $0.23 \mathrm{~m}$ to minimize the slow pyrolysis of biomass caused by radiative heat transfer during the pre-heating time. Concurrently, room temperature $\mathrm{N}_{2}$ (carrier gas) is introduced into the system from the gas inlet at the reactor wall. The flow rate of $\mathrm{N}_{2}$ is controlled by an Aalborg GCF47 mass flow controller with an accuracy of $\pm 1.5 \%$. Once the upper plate and reactor wall reach the operating temperatures, the motor begins to rotate the wood chip bowl, and the upper plate driven by the hydraulic system starts moving down toward the wood chips. Ablative contact of the hot upper plate with the wood chips initiates fast pyrolysis. The produced pyrolysis vapors are then carried by $\mathrm{N}_{2}$ and quickly escape from the reactor chamber through the gas outlet enter an ice-water cooled impinger, in which heavy fractions of the bio-oil are condensed and collected. The remaining vapors flow out of the top of the impinger and enter a counter-current double-pipe condenser from the bottom, in which 50/50 vol. \% propylene glycol/water is used as cooling fluid in the outer pipe, with an inlet temperature of $-10{ }^{\circ} \mathrm{C}$. This stage collects the light (aqueous) fraction of bio-oil. The remaining cooled vapors and non-condensable gases flow through a Swagelok coalescing filter and a packed quartz wool fiber, which collect any residual aerosols and water vapors. In addition, a building vacuum was connected to the system to drive the pyrolysis vapors out of the reactor chamber. However, the non-condensable gases are sent to the receiver tank and cannot be collected for further analysis with only building vacuum installed. Thus, a parallel GAST vacuum with a gas outlet was installed for a few runs for gas 
quantification and overall mass balance calculation, though this slightly decreased bio-oil yield (more details are discussed in section 5.2). The specifications of both the building vacuum and the GAST vacuum pump are summarized in Table 1. Solid char is left on the wood chip bowl.

Table 1. Specifications of the building vacuum and GAST vacuum pump

\begin{tabular}{|l|l|l|}
\hline & Building vacuum & Vacuum pump \\
\hline Power $(\mathrm{W})$ & $3.50 \times 10^{3}$ & 186.43 \\
\hline Flow rate $\left(\mathrm{m}^{3} / \mathrm{s}\right)$ & $8.02 \times 10^{-4}$ & $6.61 \times 10^{-4}$ \\
\hline Vacuum level $(\mathrm{Pa})$ & $7.45 \times 10^{4}-8.47 \times 10^{4}$ & $8.47 \times 10^{4}$ \\
\hline
\end{tabular}

\section{Simulation of wood chips temperature during the pre-heating time}

During the pre-heating time, the wood chips on the bowl exchanged heat with the upper plate, the reactor wall, and the $\mathrm{N}_{2}$ gas via conduction, convection, and radiation (Fig. 3). Since the wood chips did not directly contact the hot components of the reactor, we are neglecting conduction. Then the total heat rate can be expressed as:

$q_{\text {total }}=q_{\text {conv }}+q_{\text {rad }}$

where $q_{c o n v}$ and $q_{\text {rad }}$ are convection and radiation heat rates, respectively.

Employing Newton's law of cooling,

$q_{\text {conv }}=\overline{h_{\text {bowl }}} A_{\text {bowl }}\left(T_{N_{2}}-T_{\text {wood }}\right)$

where $\overline{h_{\text {bowl }}}$ is the average convection coefficient, $A_{\text {bowl }}$ is the area of the wood chip bowl bottom surface, and $T_{N_{2}}$ and $T_{\text {wood }}$ are the temperature of $\mathrm{N}_{2}$ carrier gas and wood chips, respectively. 
The radiation heat that reaches the wood chips includes radiation components from the upper plate and reactor wall. Employing the Stefan-Boltzmann law,

$$
\begin{aligned}
q_{\text {rad }} & =q_{\text {plate }}+q_{\text {wall }} \\
& =\varepsilon \sigma A_{\text {plate }} F_{13}\left(T_{\text {plate }}^{4}-T_{\text {wood }}^{4}\right)+\varepsilon \sigma A_{\text {wall }} F_{23}\left(T_{\text {wall }}^{4}-T_{\text {wood }}^{4}\right)
\end{aligned}
$$

where $\varepsilon$ is the emissivity coefficient of A240 304L stainless steel material $(\varepsilon=0.67)$ [28], $\sigma$ is the Stefan-Boltzmann constant $\left(\sigma=5.67 \times 10^{-8} \mathrm{~W} / \mathrm{m}^{2} \cdot \mathrm{K}^{4}\right), A_{\text {plate }}$ and $A_{\text {wall }}$ are the surface area of upper plate and reactor wall, $T_{\text {plate }}$ and $T_{\text {wall }}$ are the temperatures of the upper plate and reactor wall, and $F_{13}$ and $F_{23}$ are the view factors. We note that equation (3) is based on a few assumptions about the nature of the surfaces exchanging heat: a) the surfaces are opaque, b) the surfaces are gray $(\varepsilon=\alpha)$, and c) the reflective component of the radiosity (total radiative energy leaving a surface) is small by comparison with the emissive power of the surfaces, and it was neglected. This last assumption was based on the results of preliminary calculations, and it greatly simplifies the analysis of this transient problem.

Details of the energy balance for each component and the selection and calculation of the parameters in Eq. (2) and (3) are included in the supplementary material. The total heat transfer rate to the wood chips can be expressed as a function of time and $T_{\text {wood }}$. In order to simulate the temperature profile of wood chips as a function of pre-heating time, a numerical integration has been employed, where the total time can be divided by a small time interval $(\Delta t=1 \mathrm{~s})$. According to the energy balance within the time interval, the temperature of biomass after each time interval is given below:

$$
T_{\text {wood }}^{i+1}=T_{\text {wood }}^{i}+\frac{q_{\text {total }}^{i} \Delta t}{m_{\text {wood }} C_{p, \text { wood }}}
$$


where $T_{\text {wood }}^{i}$ and $T_{\text {wood }}^{i+1}$ are the temperatures of wood chips at the beginning and at the end of the time interval, respectively. $m_{w o o d}$ is the mass of wood chips $\left(m_{w o o d}=50 \mathrm{~g}\right)$ and $c_{p, w o o d}$ is the heat capacity of wood, which is also a function of $T_{\text {wood }}$. The temperatures of the upper plate and reactor wall, $T_{\text {plate }}$ and $T_{\text {wall }}$, are functions of time and were evaluated using energy balances. Matlab was used to do the simulation. All the parameters used for the simulation are summarized in Table 2.

Table 2. Parameters used for simulation

\begin{tabular}{|c|c|}
\hline Symbol & Physical meaning \\
\hline$q_{\text {total }}$ & Total heat rate \\
\hline$q_{\text {conv }}$ & Convection heat rate \\
\hline$q_{\text {rad }}$ & Radiation heat rate \\
\hline$\overline{h_{\text {bowl }}}$ & Average convection coefficient \\
\hline$A_{\text {bowl }}$ & Area of the wood chip bowl bottom surface \\
\hline$T_{N_{2}}$ & $\mathrm{~N}_{2}$ carrier gas temperature \\
\hline$T_{\text {wood }}$ & Wood chips temperature \\
\hline$q_{\text {plate }}$ & Radiation heat rate from upper plate \\
\hline$q_{\text {wall }}$ & Radiation heat rate from reactor wall \\
\hline$\varepsilon$ & Emissivity coefficient of A240 304L \\
\hline$\sigma$ & Stefan-Boltzmann constant \\
\hline$A_{\text {plate }}$ & Surface area of upper plate \\
\hline$A_{\text {wall }}$ & Surface area of reactor wall \\
\hline$T_{\text {plate }}$ & Upper plate temperature \\
\hline$T_{\text {wall }}$ & Reactor wall temperature \\
\hline$F_{13}, F_{23}$ & View factors \\
\hline$m_{\text {wood }}$ & Mass of wood chips \\
\hline
\end{tabular}




\begin{tabular}{|c|c|}
\hline$c_{p, \text { wood }}$ & Wood heat capacity \\
\hline$\Delta t$ & Time interval \\
\hline
\end{tabular}

\section{Experimental}

\subsection{Feedstock}

The feedstock used in this study was beetle-killed lodgepole pine (Pinus contorta) purchased from Forest Concepts, LLC. These trees were standing dead trees for 2-4 years before harvesting and had lost their needles. Prior to the experiment, the feedstock was chipped, ground, and sieved into three different sizes: $2 \times 2 \mathrm{~mm}, 5 \times 15 \mathrm{~mm}$, and $10 \times 20 \mathrm{~mm}$. Moreover, a small wood rod sample ( 35 dia. $\times 200 \mathrm{~mm}$ ) was used. All of these samples are shown in Fig. 4. The composition of the feedstock is given in Table 3. Briefly, the proximate analysis was carried out using TGA, the ultimately analysis was performed using an elemental analyzer (Series II 2400, PerkinElmer), and the chemical composition was measured according to the "Standard Biomass Analytical Procedures" developed by the National Renewable Energy Laboratory [10,11].

Table 3. Composition of beetle-killed lodgepole pine feedstock[10, 11]

\begin{tabular}{|c|c|c|c|c|}
\hline \multicolumn{5}{|c|}{ Proximate analysis (wt. \%) } \\
\hline Moisture & Ash & \multicolumn{2}{|c|}{ Volatile } & Fixed carbon \\
\hline 7.30 & 0.26 & \multicolumn{2}{|c|}{82.29} & 10.15 \\
\hline \multicolumn{5}{|c|}{ Ultimate analysis (wt. \%) ${ }^{\mathrm{a}}$} \\
\hline $\mathrm{C}$ & $\mathrm{H}$ & & $\mathrm{N}$ & HHV $(\mathrm{MJ} / \mathrm{kg})^{\mathrm{d}}$ \\
\hline 49.62 & 6.37 & & 0.44 & 20.34 \\
\hline \multicolumn{5}{|c|}{ Chemical composition (wt. \%) ${ }^{\mathrm{a}}$} \\
\hline \multicolumn{2}{|c|}{ Extractives $^{\text {a }}$} & Carbohydrates $^{b}$ & \multicolumn{2}{|r|}{ Lignin ${ }^{b}$} \\
\hline \multicolumn{2}{|c|}{5.48} & 61.18 & \multicolumn{2}{|r|}{28.84} \\
\hline
\end{tabular}

a. wt.\% of oven dry wood

b. wt.\% of oven dry extractive-free wood

c. O wt.\% was measured with O-mode using an elemental analyzer (Series II 2400, PerkinElmer). 
d. $\mathrm{HHV}(\mathrm{MJ} / \mathrm{kg})=\mathrm{C} \% \times 0.3578+\mathrm{H} \% \times 1.1356+\mathrm{N} \% \times 0.0594-\mathrm{O} \% \times 0.0854-0.974[10]$

\subsection{Fast pyrolysis in the ablative reactor}

The ablative pyrolysis reactor system described in section 2 was used to carry out the fast pyrolysis of wood chips. Except for the small wood rod (100 g), $50 \mathrm{~g}$ wood crumbles or chips were used for each run. All the experiments reported herein were conducted at a pyrolysis temperature (upper plate temperature) of 500 or $550{ }^{\circ} \mathrm{C}$ with a reactor wall temperature of $300{ }^{\circ} \mathrm{C}$. The applied pressure against the wood chips was $0.5 \mathrm{bar}$, the rotation speed of the wood chip bowl was $100 \mathrm{rpm}$, and the run time was $3 \mathrm{~min}$. $\mathrm{N}_{2}$ was used as carrier gas. The selection of $\mathrm{N}_{2}$ flow rate and vacuum suction is discussed in section 5.2. After pyrolysis, the char left on the wood chip bowl was collected and weighed to determine its yield. Before and after each experiment, the impinger, condenser, and filter were weighed to calculate the total bio-oil yield. Non-condensable gases were quantified when a parallel vacuum pump was installed. The total volume of non-condensable gases was equal to the difference of the final and initial gas meter reading subtracted the total volume of $\mathrm{N}_{2}$ carrier gas. An average molecular weight was determined by GC/TCD-FID analysis. Assuming the non-condensable gases as an ideal gas, the mass of gas produced was then calculated using the ideal gas law.

\subsection{Fast pyrolysis in the fluidized bed reactor}

For comparison purposes, fast pyrolysis of beetle-killed lodgepole pine samples was also carried out in a lab-scale continuous bubbling fluidized bed reactor (the most common reactor used for fast pyrolysis). The schematic diagram of the reactor is shown in Fig. 5. In this system, the beetle-killed lodgepole pine sample was first ground and sieved to a particle size of $<1 \mathrm{~mm}$ to ensure rapid heat transfer rates in the reactor. The biomass was then placed in the hopper. While 
the system was pre-heated, $\mathrm{N}_{2}$ was used to purge any oxygen present in the system. When the system reached $500{ }^{\circ} \mathrm{C}$, biomass at a rate of $0.6 \mathrm{~kg} / \mathrm{h}$ was fed into the reactor by the screw auger. The reactor is a straight tube with an inner diameter of $0.038 \mathrm{~m}$ and a length of $0.9 \mathrm{~m} .500 \mathrm{~g}$ alumina sand was used as heating media. $\mathrm{N}_{2}$ with a flow rate of 30 SLPM was used as carrier gas and the residence time of pyrolysis vapors in the reactor was around $1 \mathrm{~s}$. At the outlet of the reactor, a cyclone was used to separate the char from the pyrolysis vapors at a temperature of $325^{\circ} \mathrm{C}$. Vapors then flowed through an impinger, three counter-current double-pipe condensers (at $5{ }^{\circ} \mathrm{C}$ ), and a coalescing filter for condensation. Non-condensable gases were collected at the end of the system using a gas sampling bag. The char and sand were removed from the reactor and cyclone and weighed when they were cooled to room temperature. The mixture was then burned in a muffle furnace at $600{ }^{\circ} \mathrm{C}$ for $6 \mathrm{~h}$, and the residues were weighed after cooling down for determination of char yield. The yield of bio-oil and non-condensable gases were determined in a similar way to what is reported for the ablative unit.

\subsection{Product analysis}

The bio-oil samples were used for analysis as collected, since no solid char was observed. Prior to the analysis, all bio-oil samples were stored in a refrigerator.

The moisture content of bio-oil was determined using a Karl Fischer titrator (V20, Mettler Toledo). The test method followed the ASTM E203 standard for water using Hydranalcomposite $5 \mathrm{~K}$ reagent.

GC/MS-FID (QP2010, Ultra, Shimadzu) was used to determine the chemical composition of bio-

oil using methanol as solvent. The separation of different compounds was achieved by a SHRXI5MS capillary column $(30 \mathrm{~m} \times 0.25 \mathrm{~mm}$ I.D. $\times 0.25 \mu \mathrm{m}$ film thickness $)$ The $\mathrm{GC}$ inlet 
temperature was $300{ }^{\circ} \mathrm{C}$, and the inlet split ratio was $30: 1$. The oven temperature was

programmed from $40{ }^{\circ} \mathrm{C}$ to $300{ }^{\circ} \mathrm{C}$ with a ramp of $10{ }^{\circ} \mathrm{C} / \mathrm{min}$. The initial and final temperatures were held for 4 and 5 min, respectively. Compounds in bio-oil were identified by mass spectra comparison with NIST 2010 library, and were quantified by FID using external standards (43 compounds were identified and quantified using 20 standards).

The elemental composition of bio-oil and biochar were measured using an elemental analyzer (Series II 2400, PerkinElmer).

The collected non-condensable gases were analyzed using GC/TCD-FID with a SUPELCO 60/80 Carboxen-1000 packed column (4.6 m × $2.1 \mathrm{~mm}$ I.D. $\times 0.5 \mu \mathrm{m}$ film thickness). Helium with a flow rate of $35 \mathrm{~mL} / \mathrm{min}$ was used as carrier gas. The oven temperature was programed from $40^{\circ} \mathrm{C}(5 \mathrm{~min})$ to $225^{\circ} \mathrm{C}(10 \mathrm{~min})$ at a heating rate of $20^{\circ} \mathrm{C} / \mathrm{min}$. Standard curves were prepared from individual gas (i.e. $\mathrm{N}_{2}, \mathrm{CH}_{4}, \mathrm{CO}$, and $\mathrm{CO}_{2}$ ) for quantification.

\section{Results and discussion}

\subsection{Wood chips temperature during the pre-heating time}

The ablative pyrolysis reactor we designed is a semi-batch reactor. Prior to heating up the system, wood chips are loaded on the wood chip bowl. Due to the radiation from the hot components, the temperature of the wood chips may increase as we pre-heat the upper plate and reactor wall to the operating temperature. However, biomass has been reported to slowly decompose at about $200{ }^{\circ} \mathrm{C}$, which negatively affects bio-oil yield [29]. Thus, prior to ablative pyrolysis, the temperature profile of the wood chips during pre-heating time in our system was evaluated and controlled to minimize the extent of slow pyrolysis before the run. 
Fig. 6 is the graphical description of how the temperature of the wood chips varies with the preheating time, comparing simulation results with experimental measurements. As the temperatures of the upper plate and the reactor wall increase, the temperature of the wood chips gradually increases. When the upper plate is at $550{ }^{\circ} \mathrm{C}$ and the reactor wall is at $300{ }^{\circ} \mathrm{C}$, the temperature of the wood chips is around $200{ }^{\circ} \mathrm{C}$. This indicates that the extent of slow pyrolysis of wood chips during the pre-heating time in the semi-batch ablative reactor is small. The results derived from our calculation are in agreement with the measurements.

\subsection{Minimizing the vapor residence times}

A short vapor residence time is necessary to achieve a high yield of liquid bio-oil in fast pyrolysis. Long vapor residence times promote secondary reactions of pyrolysis vapors, favoring gas and char production [30, 31]. In our ablative pyrolysis reactor, the $\mathrm{N}_{2}$ flow rate is an important parameter affecting the vapor residence time. Thus, the effect of $\mathrm{N}_{2}$ flow rate on the product yield has been studied, and the results are shown in Table 4. All the experiments were performed using $5 \times 15 \mathrm{~mm}$ wood chips at $550{ }^{\circ} \mathrm{C}$. As the $\mathrm{N}_{2}$ flow rate increased from 15 to 40 SLPM, the yield of bio-oil did not appear to increase (41.6 wt. \% compared to $43.0 \mathrm{wt}$. \%), and the char yield only slightly decreased from $26.0 \mathrm{wt} . \%$ to $23.7 \mathrm{wt} . \%$. The slight difference may be due to relatively short vapor residence time when using higher flow rate, 40 SPLM. However, both conditions still showed low yields of bio-oil and high yields of char, indicating the occurrence of secondary reactions to a large extent due to the long vapor residence time.

Table 4. Product yield at different $\mathrm{N}_{2}$ flow rates and vacuum conditions

\begin{tabular}{|l|l|l|l|l|l|}
\hline $\mathrm{N}_{2}$ flow rate (SLPM) & 15 & 40 & 15 & 0 & 15 \\
\hline Vacuum condition & No & No & B & B & B + P \\
\hline Product yield (wt. \%) \\
\hline Bio-oil & 41.6 & 43.0 & 52.8 & 48.4 & 47.0 \\
\hline
\end{tabular}




\begin{tabular}{|l|l|l|l|l|l|}
\hline Char & 26.0 & 23.7 & 19.7 & 26.1 & 26.4 \\
\hline Non-condensable gases & NA & NA & NA & NA & 15.8 \\
\hline
\end{tabular}

B: building vacuum; P: vacuum pump; NA: not available

The use of vacuum in fast pyrolysis has been investigated by previous works and showed advantages of shortening vapor residence time and reducing occurrence and intensity of secondary reactions, thereby improving bio-oil yield $[32,33]$. Thus, the building vacuum (specifications provided in Table 1) was used in our reactor system. The suction provided by the vacuum prevents pyrolysis vapors from staying inside the reactor chamber and directs them towards the reactor outlet, escaping the chamber quickly instead of circulating inside the chamber. Two experiments were performed using the building vacuum with 15 SLPM $\mathrm{N}_{2}$ flow rate or without $\mathrm{N}_{2}$ flow rate. Both conditions increased bio-oil yield, and the utilization of building vacuum combined with $15 \mathrm{SLPM} \mathrm{N}_{2}$ flow rate significantly increased bio-oil yield by more than $10 \mathrm{wt}$. \%, decreasing char yield by $6 \mathrm{wt} . \%$. Therefore, $\mathrm{N}_{2}$ flow rate of 15 SLPM combined with building vacuum were selected to use for the remaining experiments in this study. One disadvantage of using the building vacuum is that the non-condensable gases could not be analyzed and quantified. In order to quantify the gas production and thereby calculate the total mass balance, a vacuum pump with a gas outlet was installed in parallel in a single run. From this run, the bio-oil, char, and non-condensable gases yields were 47 wt. \%, 26 wt. \%, and 15.8 wt. \%, respectively. The total mass balance was about 90 wt. \%. The composition of noncondensable gases was analyzed in GC/TCD-FID, including 38.5 wt. \% of CO, 57.3 wt. \% of $\mathrm{CO}_{2}$, and 4.2 wt. $\%$ of $\mathrm{CH}_{4}$. The relatively lower bio-oil yield and higher char yield resulted from the longer residence time caused by weaker suction in the parallel vacuum system. Additionally, the results from preliminary experiments indicated that cracking reactions of volatiles into permanent gases were important at $550{ }^{\circ} \mathrm{C}$, leading to about $8 \mathrm{wt} . \%$ lower yields of bio-oil at 
$550^{\circ} \mathrm{C}$ than at $500{ }^{\circ} \mathrm{C}$. For this reason, we selected $500{ }^{\circ} \mathrm{C}$ as the temperature for the rest of the experiments in this study.

\subsection{Ablative pyrolysis of wood crumbles, chips, and rods}

Feedstock particle size is one of the important parameters affecting bio-oil yield in fast pyrolysis, and usually very small $(1-2 \mathrm{~mm})$ particles are required to provide rapid heating and achieve a high yield of bio-oil[15]. Shen et al. investigated the effect of particle size on the fast pyrolysis of oil mallee woody biomass in a fluidized bed reactor, and they found that the bio-oil yield dramatically decreased by $12-14 \%$ as biomass particle size increased from $0.3 \mathrm{~mm}$ to $1.5 \mathrm{~mm}$ [34]. Similar results were also observed by Salehi et al. [35]. The novel ablative pyrolysis reactor we designed and constructed in this study aims to convert entire wood chips into a high yield of bio-oil. The wood samples with different particle sizes (i.e. $2 \times 2 \mathrm{~mm}$ wood crumbles, $5 \times 15$ $\mathrm{mm}$ and $10 \times 20 \mathrm{~mm}$ wood chips, and a 35 dia. $\times 200 \mathrm{~mm}$ wood rod) were used as feedstocks to study the effect of particle size on the product yield and distribution. All these experiments were operated at a pyrolysis temperature of $500{ }^{\circ} \mathrm{C}$, with $\mathrm{N}_{2}$ carrier gas at a flow rate of 15 SLPM and with building vacuum suction. Fig. 7 shows the product yield as a function of particle size. Two replicates were performed using $5 \times 15 \mathrm{~mm}$ and $10 \times 20 \mathrm{~mm}$ wood chips to obtain standard deviations for the yield of bio-oil ( \pm 1.4 wt. \%) and char ( \pm 0.9 wt. \%), and the standard deviations obtained from $10 \times 20 \mathrm{~mm}$ were applied to the results from $2 \times 2 \mathrm{~mm}$ wood crumbles and 35 dia. $\times 200 \mathrm{~mm}$ wood rod. Considering the standard deviations, there was no difference in yields between the $2 \times 2 \mathrm{~mm}$ crumbles and the $5 \times 15 \mathrm{~mm}$ and $10 \times 20 \mathrm{~mm}$ wood chips. The yields of bio-oil and char were about $60 \mathrm{wt} . \%$ and $18 \mathrm{wt} . \%$, respectively. These results support the hypothesis that the size of the wood chips does not affect the ablative process [19]. Note how this conclusion is in stark contrast with the literature reports for effects of particle size obtained 
in other types of reactors. The system also successfully pyrolyzed an entire wood rod (35 dia. $\times$ $200 \mathrm{~mm}$ ), though this case shows lower yield of bio-oil (47 wt. \%) and higher yield (25 wt. \%) of char than wood chips. When $50 \mathrm{~g}$ of wood crumbles/chips was loaded in the wood chip bowl, the resulting thickness was around $5 \mathrm{~mm}$, whereas the thickness of the wood rod was $35 \mathrm{~mm}$. Using the wood rod as feedstock; therefore, possibly led to more char due to the poor thermal conductivity of the wood and char, lowering the bio-oil yield.

\subsection{Comparison with a lab-scale fluidized bed reactor}

The fluidized bed reactor is one of the most popular reactor configurations for fast pyrolysis of biomass due to its high bio-oil yield and ready scale-up [2]. Thus, the results from fast pyrolysis of wood chips $(10 \times 20 \mathrm{~mm})$ in our ablative pyrolysis reactor were compared to those obtained from a lab-scale fluidized bed reactor, using the same feedstock and pyrolysis temperature $\left(500{ }^{\circ} \mathrm{C}\right)$, but a much smaller particle size $(<1 \mathrm{~mm})$. In the fluidized bed reactor, $64 \mathrm{wt} . \%$ yield of bio-oil, 10 wt. \% of char, and 18 wt. \% of non-condensable gases were observed (Fig. 8). Similar product yields from fast pyrolysis of pine wood in a fluidized bed reactor were also reported in the literature $[36,37]$. Comparing to these results, fast pyrolysis of wood chips in the ablative reactor showed similar product yields, with slightly less bio-oil ( $\sim 5$ wt. $\%)$ and gas $(\sim 4$ wt. \%), and more char (9 wt. \%). The gas yield from ablative pyrolysis was calculated by difference, assuming 90 wt. \% was the total mass balance for each run (section 5.2).

The composition of the bio-oil and char from both processes were also analyzed and compared. The water content of bio-oil from the ablative pyrolysis reactor and fluidized bed reactor were $34 \%$ and $26 \%$, respectively. This water came from both the original moisture in feedstocks and the products of dehydration reactions during the pyrolysis process [38]. The original moisture of biomass could be evaporated during the pre-heating time in the semi-batch ablative reactor, but it 
will eventually enter the collectors and mix with bio-oil. Since the feedstocks used in these two reactors had similar moisture content $(\sim 7 \%)$, the higher water content of bio-oil from the ablative pyrolysis reactor may have resulted from the relatively longer vapor residence times, promoting secondary dehydration reactions and leading to water production [39]. Fig. 9 shows the organic compound selectivity of bio-oils from the ablative pyrolysis reactor (for wood chips and also the wood rod) and the fluidized bed reactor. The bio-oil from both reactors were a mixture of oxygenates, including anhydrosugars (e.g levoglucosan), furans (e.g. furfural, furanmethanol, and 5-hydroxymethylfurfural), guaiacols (e.g. guaiacol, methylguaiacol, and eugenol), phenols (e.g. phenol, cresol, and catechol), esters (e.g. acetonyl acetate and propyl acetate), aldehydes (e.g. glycolaldehyde and succindialdehyde), ketones (e.g. acetol and cyclopentenone), and acids (e.g. formic acid and acetic acid). Both bio-oils had a higher selectivity to anhydrosugars (20$23 \%$ ) and guaiacols (16-26\%). For the ablative reactor, we observed that the use of wood chips or wood rods led to essentially the same selectivity. Compared to the bio-oil from the fluidized bed reactor, the bio-oil from the ablative reactor had a relatively higher selectivity to guaiacols, lower selectivity to acids, and similar selectivity to other compounds. Though the vapor residence time in the ablative reactor was speculated to be longer than that in the fluidized bed reactor, the temperature of the vapors in the ablative reactor chamber was close to the wall temperature of $300{ }^{\circ} \mathrm{C}$ (only the metallic surface is at $500{ }^{\circ} \mathrm{C}$ ), whereas the temperature of vapors in the fluidized bed reactor chamber was much higher $\left(500^{\circ} \mathrm{C}\right)$. The higher vapor temperature in the fluidized bed reactor may be the reason for its higher selectivity to acids and lower selectivity to guaiacols. Patwardhan et al. [40] studied the fast pyrolysis of lignin in the Py-GC/MS and observed increasing selectivity to acetic acid as temperature increased. They also found that the presence of acetic acid promoted the oligomerization of guaiacols. Zhou et al. [41] fast pyrolyzed 
lignin using Py-GC/MS and also reported that the selectivity to guaiacols decreased with increasing temperature. These previous works are consistent with our experimental results and hypothesis that explain the trends observed. Table 4 shows the elemental composition of the biooil and char from the ablative pyrolysis reactor and fluidized bed reactor, from which the higher heating value (HHV) of bio-oil and char were calculated using an empirical equation. Due to the higher water content, the bio-oil from the ablative reactor had a slightly lower carbon content (37.15\% vs. $42.78 \%$ ), higher oxygen content ( $54.05 \%$ vs. $49.27 \%)$, and thereby lower HHV $(14.31 \mathrm{MJ} / \mathrm{kg}$ vs. $16.86 \mathrm{MJ} / \mathrm{kg}$ ) than that from the fluidized bed reactor. Similar elemental compositions were observed for the char from both systems. The HHVs of the char from both reactors were around $29 \mathrm{MJ} / \mathrm{kg}$.

\section{Table 4. Elemental composition of bio-oil and char from ablative pyrolysis reactor and fluidized bed reactor}

\begin{tabular}{|c|c|c|c|c|}
\hline \multirow{2}{*}{$\begin{array}{c}\text { Elemental } \\
\text { composition (wt. \%) }\end{array}$} & \multicolumn{2}{|c|}{ Bio-oil } & \multicolumn{2}{c|}{ Char } \\
\cline { 2 - 5 } & Ablative & Fluidized bed & Ablative & Fluidized bed \\
\hline $\mathrm{C}$ & 37.53 & 42.78 & 74.68 & 74.09 \\
\hline $\mathrm{H}$ & 8.38 & 7.92 & 3.41 & 4.41 \\
\hline $\mathrm{O}^{\mathrm{a}}$ & 54.05 & 49.27 & 21.45 & 21.36 \\
\hline $\mathrm{N}$ & 0.03 & 0.03 & 0.17 & 0.14 \\
\hline $\mathrm{HHV}(\mathrm{MJ} / \mathrm{kg})^{\mathrm{b}}$ & 14.31 & 16.86 & 28.52 & 29.81 \\
\hline
\end{tabular}

a. calculate by difference

b. $\mathrm{HHV}(\mathrm{MJ} / \mathrm{kg})=\left(3.55 \mathrm{C}^{2}-232 \mathrm{C}-2230 \mathrm{H}+51.2 \mathrm{C} \mathrm{H}+131 \mathrm{~N}+20600\right) \times 10^{-3}[36]$

In general, compared to fast pyrolysis of $<1 \mathrm{~mm}$ wood particles in a lab-scale fluidized bed reactor, fast pyrolysis of entire wood chips in the ablative reactor showed similar product yield and composition with slightly a lower bio-oil yield, a higher water content, and a lower HHV of bio-oil. This is mainly caused by the longer vapor residence times in the ablative reactor. The large reactor chamber volume, which was selected to minimize the slow pyrolysis of wood chips during the pre-heating time in this semi-batch reactor, was the main factor increasing the vapor 
residence times. However, this problem can be easily solved by modifying this prototype ablative pyrolysis reactor system into a continuous system in the future. It has been proposed many times that it is possible to fast pyrolyze large pieces of wood in ablative reactors; however, the previously reported largest particle size used in ablative reactors to mainly produce bio-oil was only as high as $4.75-6.25 \mathrm{~mm}[19-23,25]$. To the best of our knowledge, our study is the first to report bio-oil production from fast pyrolysis of entire wood chips and wood rods, and the yield of bio-oil from wood chips (with size of up to $20 \mathrm{~mm}$ ) was as high as $60 \mathrm{wt} . \%$. The chopping/grinding costs would be significantly reduced by using wood chips as feedstock, which contribute to $7-9 \%$ of overall production costs. It is important to note that ablative pyrolysis is a process based on the availability of a hot metallic surface area for contact/heat transfer, and for this reason its application in large-scale settings would be difficult. However, for small scale, mobile pyrolysis units intended for the disposal of forest residues, ablative pyrolysis of entire wood chips/logs is an interesting option, and the findings of this work have the potential to lead to future developments for this application.

\section{Conclusion}

A novel prototype lab-scale ablative fast pyrolysis reactor was designed and constructed in this study to convert entire wood chips and wood rods into bio-oil. Prior to ablative pyrolysis, the temperature profile of wood chips during the pre-heating time in this semi-batch reactor was evaluated and controlled to minimize the extent of slow pyrolysis. The results from our calculations were in good agreement with experimental measurements and verified that the extent of slow pyrolysis of wood chips during the pre-heating time was small in the ablative pyrolysis unit. The beetle-killed lodgepole pine wood samples with different particle sizes (i.e. 2 $\times 2 \mathrm{~mm}$ wood crumbles, $5 \times 15 \mathrm{~mm}$ and $10 \times 20 \mathrm{~mm}$ wood chips, and a 35 dia. $\times 200 \mathrm{~mm}$ wood 
rod) were used as feedstocks, and the results of this work confirm that the bio-oil yield from ablative pyrolysis is not dependent of the particle size in the range studied. Ablative pyrolysis of wood chips $(10 \times 20 \mathrm{~mm})$ led to similar product yield as $2 \times 2 \mathrm{~mm}$ wood crumbles, and the biooil yield was as high as $60 \mathrm{wt} . \%$. These results were similar to those from fast pyrolysis of small wood particles $(<1 \mathrm{~mm})$ in a fluidized bed reactor. This study confirmed the hypothesis that high bio-oil yields can be obtained from ablative pyrolysis of entire wood chips. This information has the potential to save in grinding costs for mobile pyrolysis units.

\section{Acknowledgement}

The authors would like to acknowledge the financial support from USDA NIFA (Grant No. 2012-34638-2020). We would also like to thank Forest Concepts for providing wood chips and wood rods, and Alaskan Copper Company for the detailed drawings, manufacturing, and maintenance of the ablative reactor. We also thank Jingda Wu from the University of Washington for his help on Matlab coding.

\section{References}

[1] Ragauskas AJ, Williams CK, Davison BH, Britovsek G, Cairney J, Eckert CA, Frederick WJ, Hallett JP, Leak DJ, Liotta CL. The path forward for biofuels and biomaterials. Science 2006; 311: 484-489.

[2] Resende FLP. Chapter 1: Reactor configurations and design parameters for thermochemical conversion of biomass into fuels, energy, and chemicals. In: Shi F, editor. Reactor and Process Design in Sustainable Energy Technology. Elesvier B.V.; 2014, p. 1-26.

[3] Bianchi D, Perego C, Capuano F. Chapter 2: Biomass transformation by thermo- and biochemical process to diesel fuel intermediates. In: Cavani F, Albonetti S, Basile F, Gandini A, 
editors. Chemicals and Fuels from Bio-Based Building Blocks, Germany: Wiley-Vch; 2016, p. 643-666.

[4] Mortensen PM, Grunwaldt J-D, Jensen PA, Knudsen K, Jensen AD. A review of catalytic upgrading of bio-oil to engine fuels. Appl Catal, A 2011; 407: 1-19.

[5] Vispute TP, Zhang H, Sanna A, Xiao R, Huber GW. Renewable chemical commodity

feedstocks from integrated catalytic processing of pyrolysis oils. Science 2010; 330: 1222-1227.

[6] Ji-Lu Z. Bio-oil from fast pyrolysis of rice husk: Yields and related properties and improvement of the pyrolysis system. J Anal Appl Pyrol 2007; 80: 30-35.

[7] Kim KH, Bai X, Rover M, Brown RC. The effect of low-concentration oxygen in sweep gas during pyrolysis of red oak using a fluidized bed reactor. Fuel 2014; 124: 49-56.

[8] Wang K, Brown RC, Homsy S, Martinez L, Sidhu SS. Fast pyrolysis of microalgae remnants in a fluidized bed reactor for bio-oil and biochar production. Bioresource Technol 2013; 127 : 494-499.

[9] Westerhof RJ, Brilman DWF, Garcia-Perez M, Wang Z, Oudenhoven SR, Kersten SR. Stepwise fast pyrolysis of pine wood. Energ Fuel 2012; 26: 7263-7273.

[10] Luo G, Resende FL. Fast pyrolysis of beetle-killed trees. J Anal Appl Pyrol 2014; 110: 100107.

[11] Luo G, Resende FL. In-situ and ex-situ upgrading of pyrolysis vapors from beetle-killed trees. Fuel 2016; 166: 367-375.

[12] USFS. 2011. Western Bark Beetle Strategy. U. S. Forest Service http://www.fs.usda.gov/Internet/FSE_DOCUMENTS/stelprdb5338089.pdf. Accessed on May 20th, 2016. 
[13] Badger PC, Fransham P. Use of mobile fast pyrolysis plants to densify biomass and reduce biomass handling costs_A preliminary assessment. Biomass Bioenerg 2006; 30: 321-325. [14] Raffelt K, Henrich E, Koegel A, Stahl R, Steinhardt J, Weirich F. The BTL2 process of biomass utilization entrained-flow gasification of pyrolyzed biomass slurries. Appl Biochem Biotech 2006; 129: 153-164.

[15] Bridgwater AV. Renewable fuels and chemicals by thermal processing of biomass. Chem Eng J 2003; 91: 87-102.

[16] Kumar A. A conceptual comparison of bioenergy options for using mountain pine beetle infested wood in Western Canada. Bioresource Technol 2009; 100: 387-399.

[17] Forest Concepts. 2014. Forest Concepts Completes US Department of Energy SBIR Phase I Project to Demonstrate Technical Feasibility of Milling Green and High Moisture Biomass to Biofuel Feedstocks. Institution. http://www.forestconcepts.com/index.php?page=04001. Accessed on May 20 2016.

[18] Lédé J. Comparison of contact and radiant ablative pyrolysis of biomass. J Anal Appl Pyrol 2003; 70: 601-618.

[19] Lédé J, Panagopoulos J, Villermaux J. Experimental Measurement of ablation rate of wood pieces, undergoing fast pyrolysis by contact with a heated wall. Prepr. Pap., Am. Chem. Soc., Div. Fuel Chem.; (United States) 1983; 38.

[20] Diebold J, Ablative pyrolysis of macroparticles of biomass, in: Proceedings of the Specialists Workshop on the Fast Pyrolysis of Biomass, Copper Mountain, Co, 1980, pp. 237. [21] Lédé J, Li HZ, Villermaux J, Martin H. Fusion-like behaviour of wood pyrolysis. J Anal Appl Pyrol 1987; 10: 291-308. 
[22] Lédé J, Panagopoulos J, Li HZ, Villermaux J. Fast pyrolysis of wood: direct measurement and study of ablation rate. Fuel 1985; 64: 1514-1520.

[23] Martin H, Lédé J, Li H, Villermaux J, Moyne C, Degiovanni A. Ablative melting of a solid cylinder perpendicularly pressed against a heated wall. Int J Heat Mass Tran 1986; 29: 14071415.

[24] Reed TB, Cowdery CD, Heat flux requirements for fast pyrolysis and a new method for generating biomass vapor, in: $193^{\text {rd }}$ National Meeting of the American Chemical Society, American Chemical Society Division of Petroleum Chemistry, 1987, pp. 5-10.

[25] Peacocke G, Bridgwater A. Ablative plate pyrolysis of biomass for liquids. Biomass Bioenerg 1994; 7: 147-154.

[26] Aston University. www.aston.ac.uk/EasySiteWeb/GatewayLink.aspx?alId=32782. Accessed on December 14th 2016.

[27] Paulsen AD, Hough BR, Williams CL, Teixeira AR, Schwartz DT, Pfaendtner J, Dauenhauer PJ. Fast pyrolysis of wood for biofuels: spatiotemporally resolved diffuse reflectance in situ spectroscopy of particles. ChemSusChem 2014; 7: 765-776.

[28] Bergman TL, Incropera FP, Lavine AS, Fundamentals of heat and mass transfer, John Wiley \& Sons, 2011.

[29] Yang H, Yan R, Chen H, Lee DH, Zheng C. Characteristics of hemicellulose, cellulose and lignin pyrolysis. Fuel 2007; 86: 1781-1788.

[30] Bridgwater A. Principles and practice of biomass fast pyrolysis processes for liquids. J Anal Appl Pyrol 1999; 51: 3-22.

[31] Bridgwater A, Meier D, Radlein D. An overview of fast pyrolysis of biomass. Org Geochem 1999; 30: 1479-1493. 
[32] Benallal B, Roy C, Pakdel H, Chabot S, Poirier M. Characterization of pyrolytic light naphtha from vacuum pyrolysis of used tyres comparison with petroleum naphtha. Fuel 1995; 74: 1589-1594.

[33] Roy C, Chaala A, Darmstadt H. The vacuum pyrolysis of used tires: End-uses for oil and carbon black products. J Anal Appl Pyrol 1999; 51: 201-221.

[34] Shen J, Wang X-S, Garcia-Perez M, Mourant D, Rhodes MJ, Li C-Z. Effects of particle size on the fast pyrolysis of oil mallee woody biomass. Fuel 2009; 88: 1810-1817.

[35] Salehi E, Abedi J, Harding T. Bio-oil from sawdust: effect of operating parameters on the yield and quality of pyrolysis products. Energ Fuel 2011; 25: 4145-4154.

[36] Desisto WJ, Hill N, Beis SH, Mukkamala S, Joseph J, Baker C, Ong T-H, Stemmler EA, Wheeler MC, Frederick BG. Fast pyrolysis of pine sawdust in a fluidized-bed reactor. Energ Fuel 2010; 24: 2642-2651.

[37] Kang B-S, Lee KH, Park HJ, Park Y-K, Kim J-S. Fast pyrolysis of radiata pine in a bench scale plant with a fluidized bed: Influence of a char separation system and reaction conditions on the production of bio-oil. J Anal Appl Pyrol 2006; 76: 32-37.

[38] Oasmaa A, Czernik S. Fuel oil quality of biomass pyrolysis oils state of the art for the end users. Energ Fuel 1999; 13: 914-921.

[39] Heo HS, Park HJ, Park Y-K, Ryu C, Suh DJ, Suh Y-W, Yim J-H, Kim S-S. Bio-oil production from fast pyrolysis of waste furniture sawdust in a fluidized bed. Bioresource Technol 2010; 101: S91-S96.

[40] Patwardhan PR, Brown RC, Shanks BH. Understanding the fast pyrolysis of lignin. ChemSusChem 2011; 4: 1629-1636. 
[41] Zhou S, Garcia-Perez M, Pecha B, Kersten SR, Mcdonald AG, Westerhof RJ. Effect of the fast pyrolysis temperature on the primary and secondary products of lignin. Energ Fuel 2013; 27: 5867-5877.

\section{Figure Captions}

Fig.1. Ablative pyrolysis reactor 
Fig. 2. Schematic diagram of the ablative reactor system

Fig. 3. Schematic diagram for radiation heat rate calculation

Fig. 4. Picture of biomass feedstock in the wood chip bowl. a) $2 \times 2$ mm wood crumbles ${ }^{\circledR}$; b) $5 \times$ $15 \mathrm{~mm}$ wood chips; c) $10 \times 20 \mathrm{~mm}$ wood chips, and d) 35 dia. $\times 200 \mathrm{~mm}$ wood rod.

Fig. 5. Schematic diagram of the fluidized bed reactor system

Fig. 6. Temperature profile of the wood chips during pre-heating time (solid lines represent results from calculation; orange circle, blue triangle, and grey square represent data from measurements)

Fig. 7. Product yield from ablative pyrolysis of wood crumbles, chips, and rods

Fig. 8. Product yield from ablative pyrolysis reactor and fluidized bed reactor

Fig. 9. Organic compound selectivity of bio-oil from ablative pyrolysis reactor and fluidized bed reactor

\section{Figure}




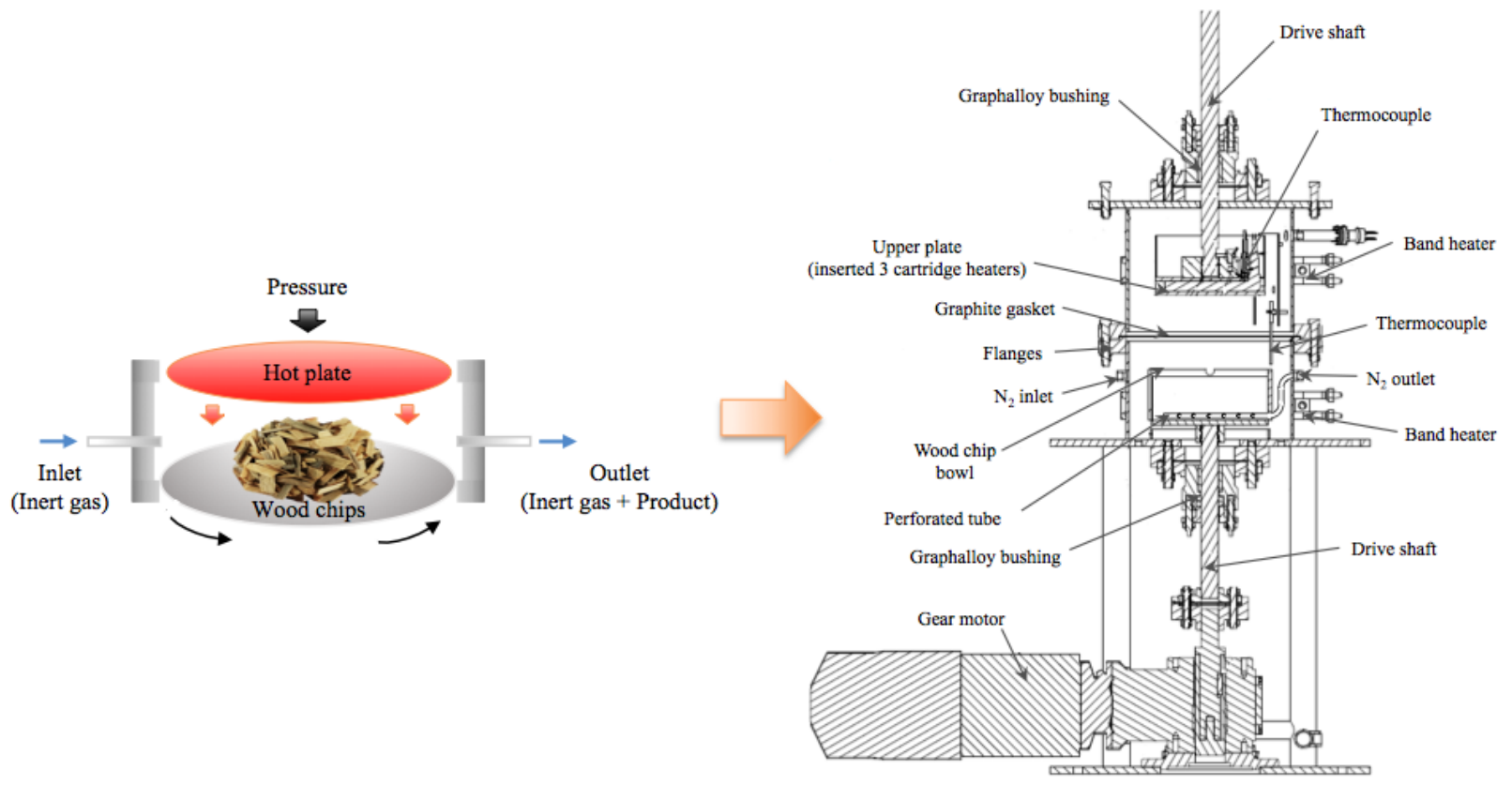

Fig.1. Ablative pyrolysis reactor 


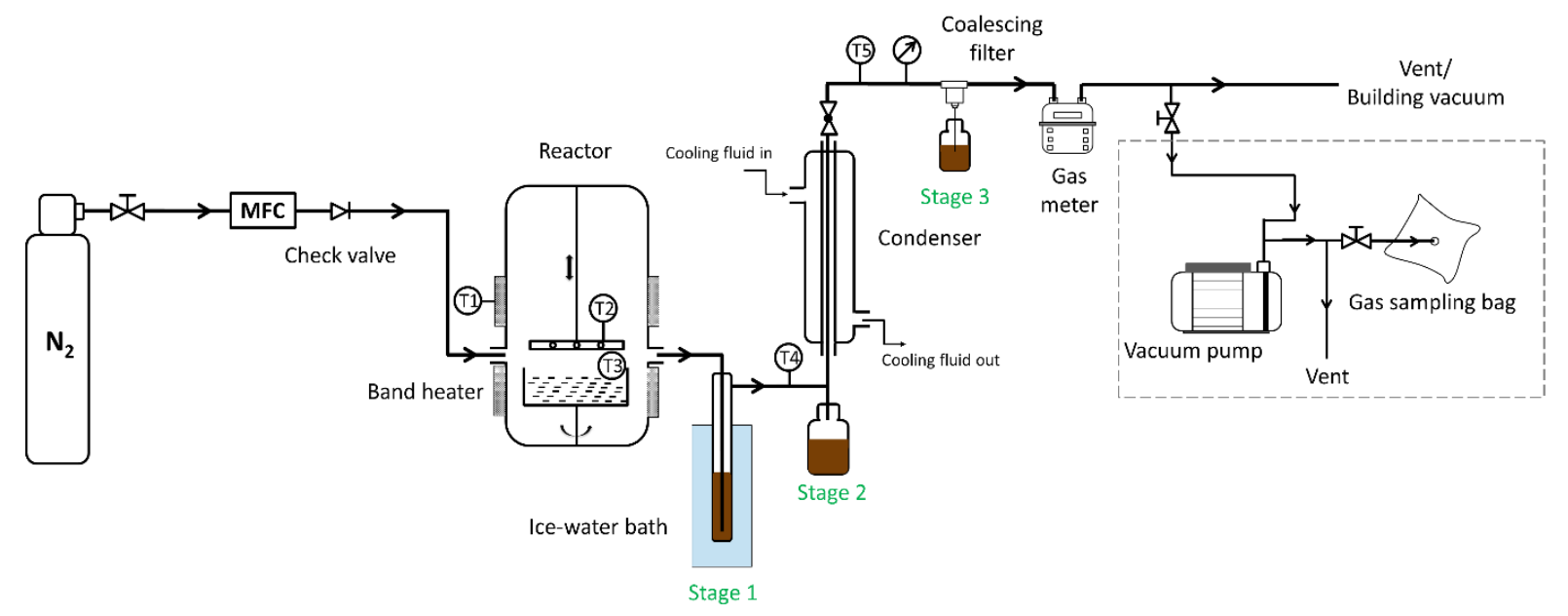

Fig. 2. Schematic diagram of the ablative reactor system 


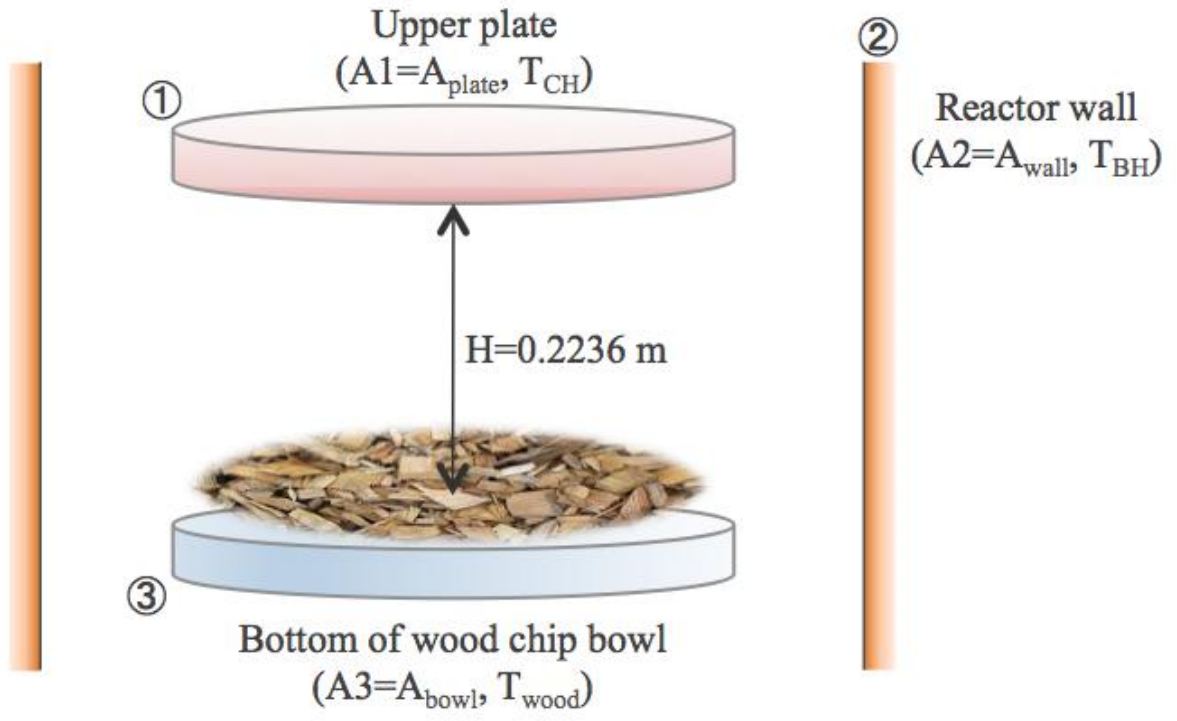

Fig. 3. Schematic diagram for radiation heat rate calculation

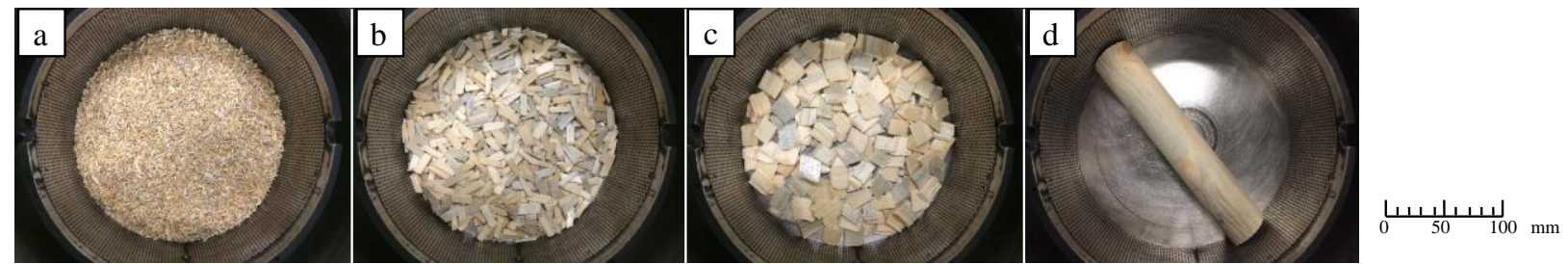


Fig. 4. Picture of biomass feedstock in the wood chip bowl. a) $2 \times 2 \mathrm{~mm}$ wood crumbles ${ }^{\circledR}$; b) $5 \times 15 \mathrm{~mm}$ wood chips; c) $10 \times 20 \mathrm{~mm}$ wood chips, and d) 35 dia. $\times 200 \mathrm{~mm}$ wood rod. 


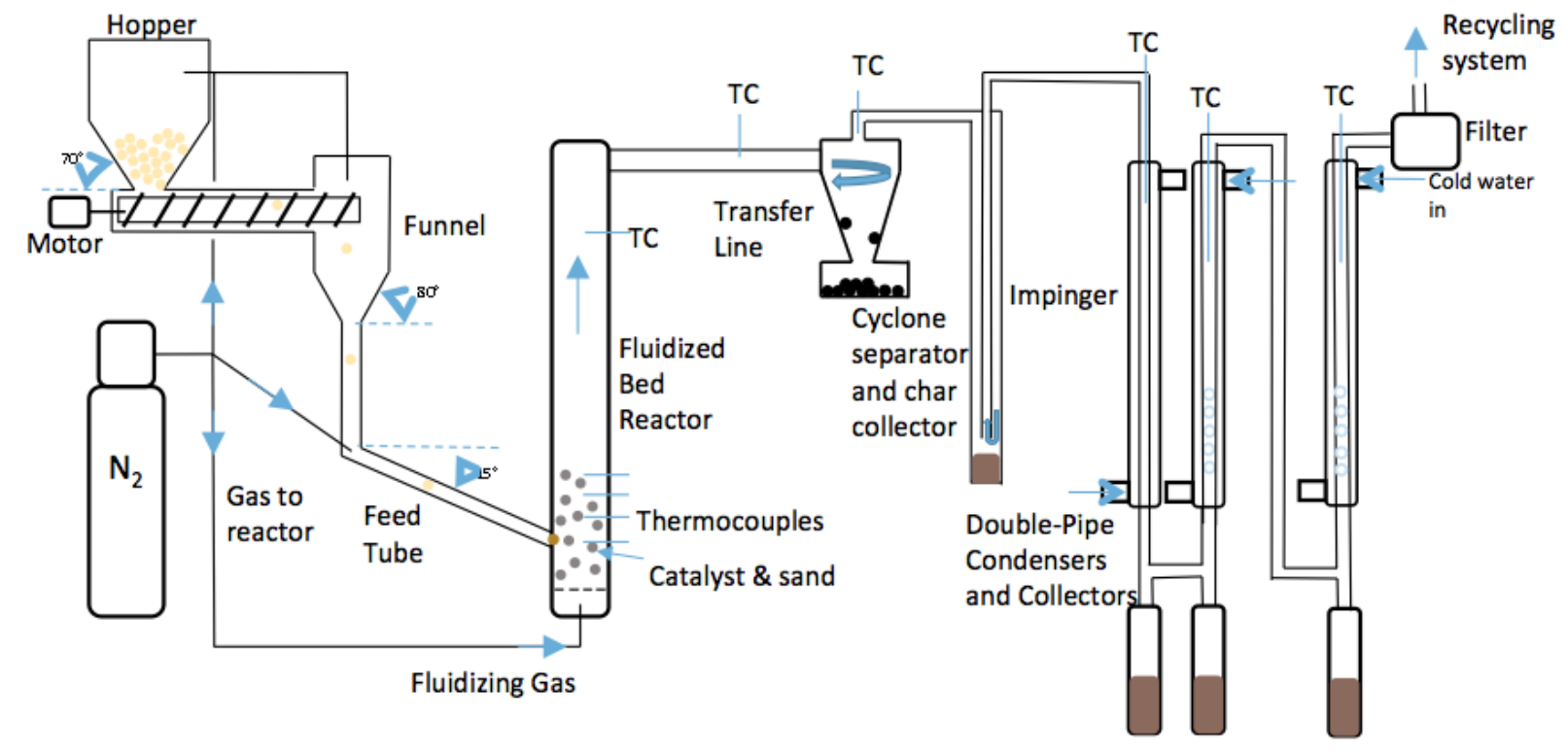

Fig. 5. Schematic diagram of the fluidized bed reactor system 


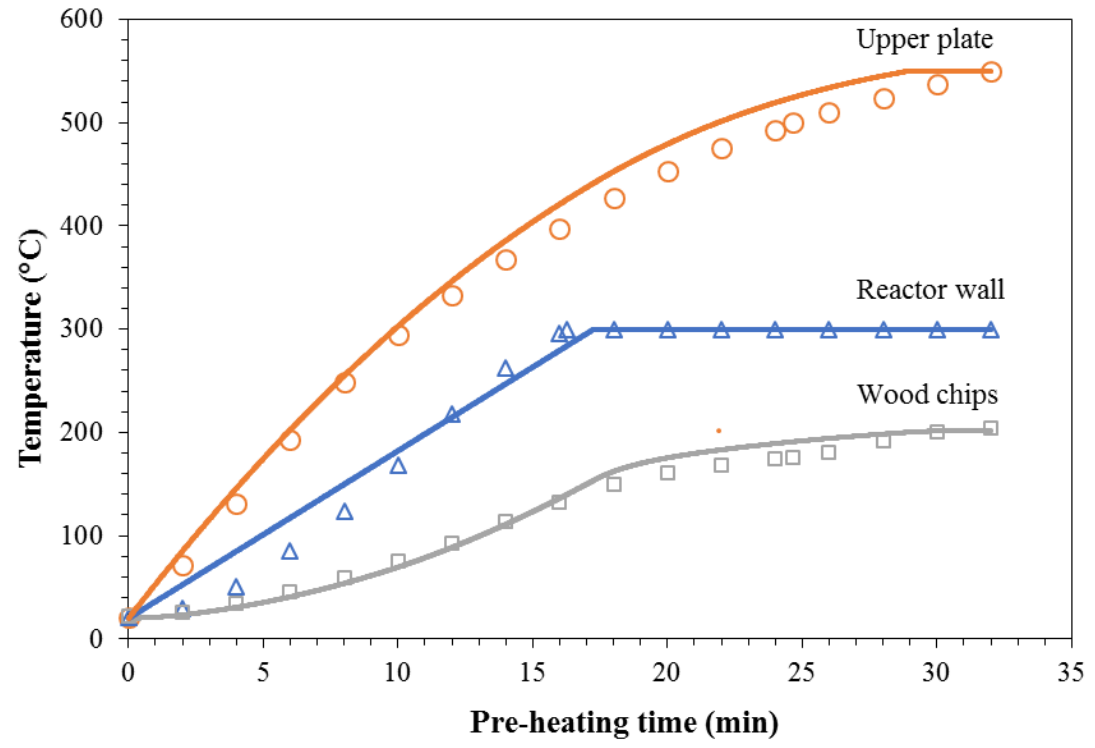

Fig. 6. Temperature profile of the wood chips during pre-heating time (solid lines represent results from calculation; orange circle, blue triangle, and grey square represent data from measurements) 


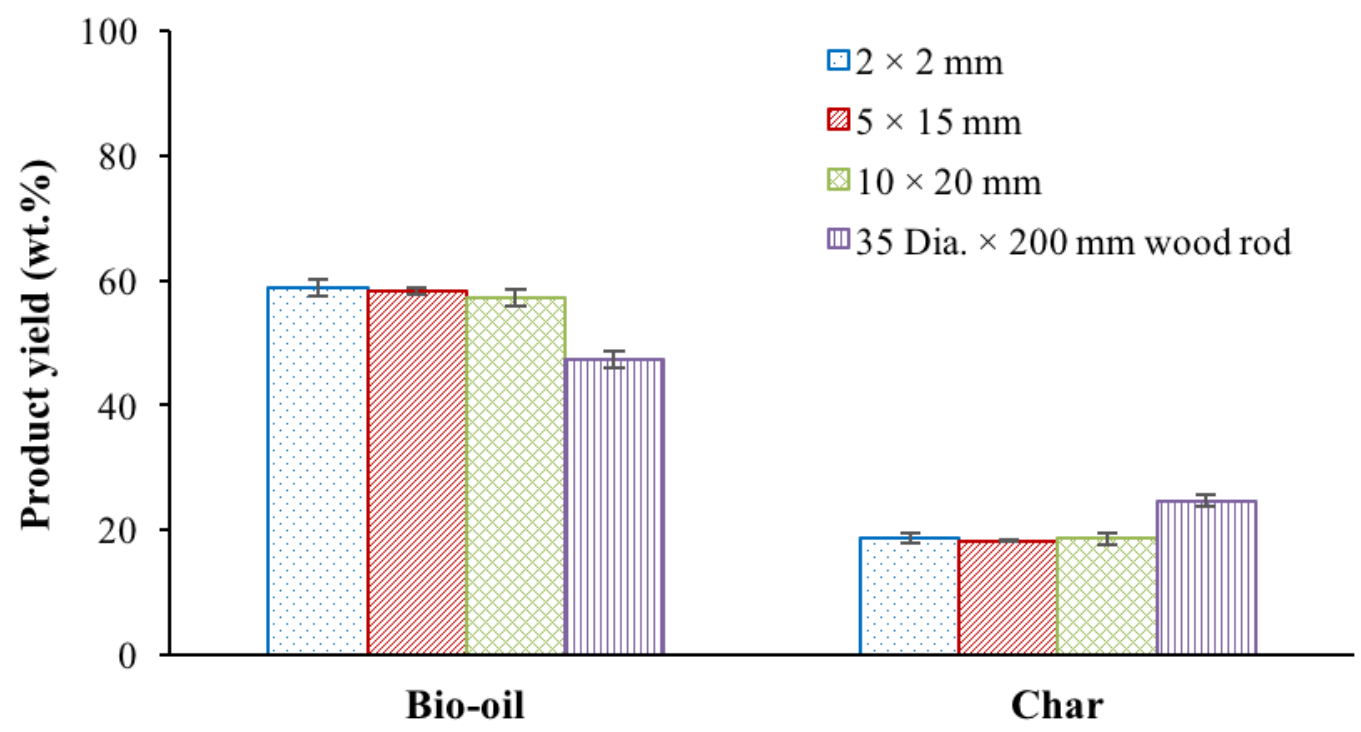

Fig. 7. Product yield from ablative pyrolysis of wood crumbles, chips, and rods 


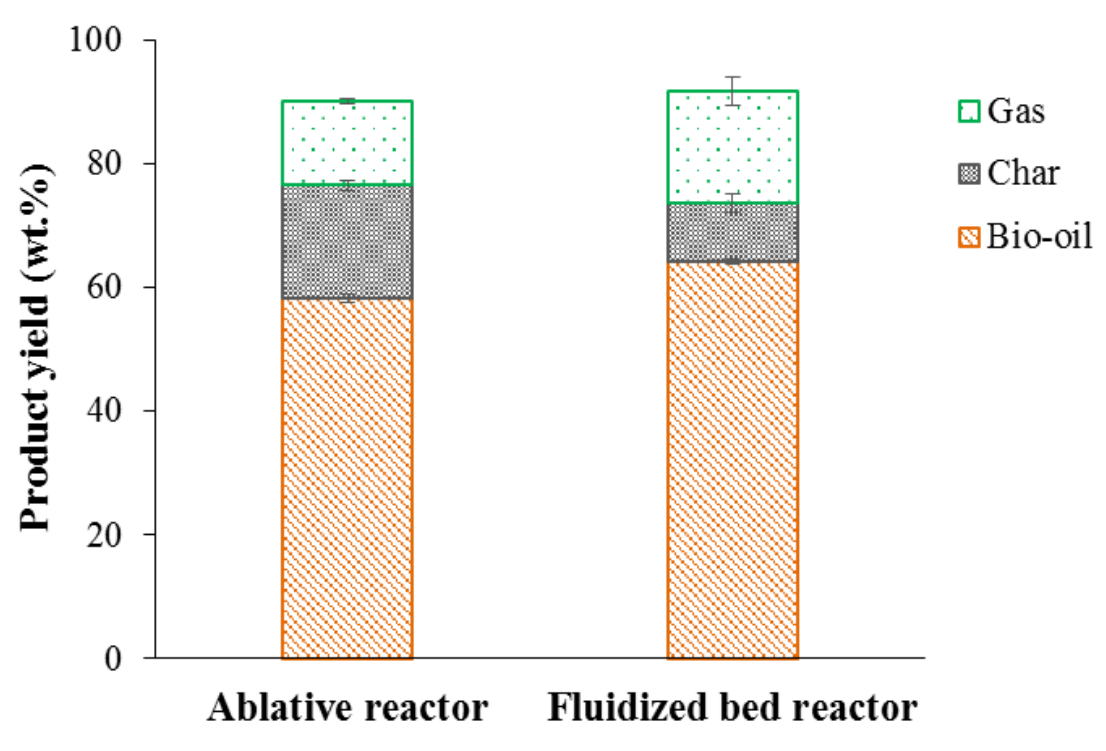

Fig. 8. Product yield from ablative pyrolysis reactor and fluidized bed reactor 


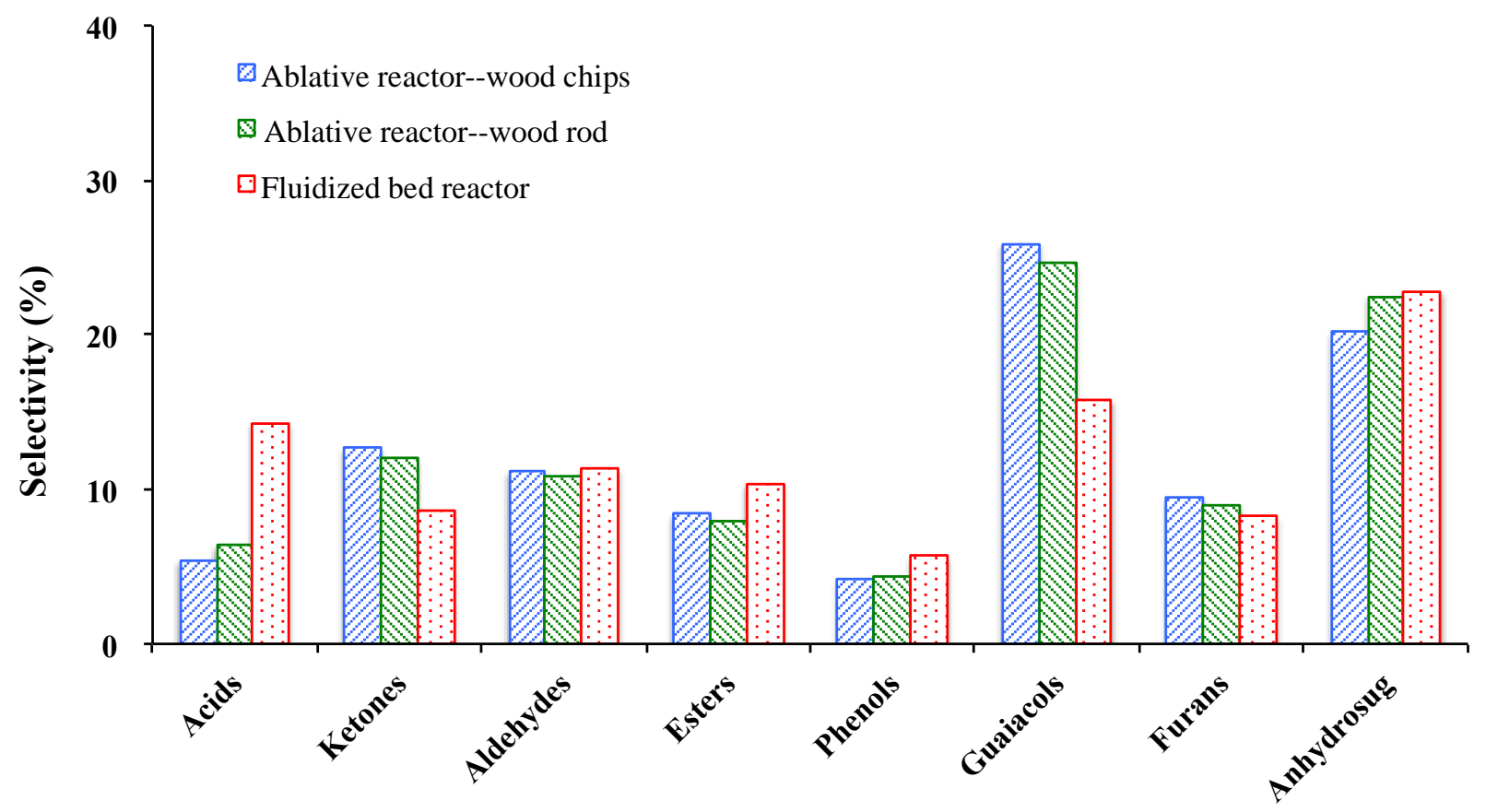

Fig. 9. Organic compound selectivity of bio-oil from ablative pyrolysis reactor and fluidized bed reactor 